\title{
Adherence and rehospitalizations in patients with schizophrenia: evidence from Japanese claims data
}

This article was published in the following Dove Press journal:

Neuropsychiatric Disease and Treatment

I April 2015

Number of times this article has been viewed

\author{
Hiroyo Kuwabara' \\ Yoshimichi Saito' \\ Jörg Mahlich ${ }^{1,2}$ \\ 'Health Economics, Janssen KK, \\ Tokyo, Japan; ${ }^{2}$ Düsseldorf Institute \\ for Competition Economics, \\ University of Düsseldorf, Düsseldorf, \\ Germany
}

Background: The aim of this study is to analyze if there is a relationship between adherence to antipsychotic medication and rehospitalization for patients diagnosed with schizophrenia in Japan.

Methods: Based on Japanese claims data, we constructed three patient groups based on their medication possession ratio (MPR). Controlling for potential confounders, a Cox proportional hazard model was employed to assess if medication adherence affects the risk of rehospitalization.

Results: Patients with good adherence (MPRs from 0.8-1.1) had the lowest rates of admission. Both poor adherence (MPRs <0.8) and overadherence (MPRs >1.1) were associated with a significant higher risk of rehospitalization with hazard ratios of 4.7 and 2.0, respectively.

Conclusion: The results of this study support the notion that good adherence to antipsychotic medication reduces the risk of rehospitalization of schizophrenia patients. Appropriate measures should be taken to improve adherence of schizophrenia patients.

Keywords: adherence, hospitalizations, schizophrenia, Japan, claims data

\section{Introduction}

Schizophrenia is a serious mental illness with considerable economic impact. It is regarded as the most expensive disorder among all psychiatric disorders in terms of health care expenditure per patient. ${ }^{1}$ A recent Japanese study estimated the annual burden of disease to exceed 3.5 million yen per patient (approximately US\$30,000). ${ }^{2}$ Most of the costs can be attributed to the loss of working ability as schizophrenia patients face a higher likelihood of being unemployed. Hospitalization has been identified as another significant cost driver not only in Japan but also in the United States ${ }^{3,4}$ and Europe. ${ }^{5,6}$ Hence, relapse prevention that helps to reduce inpatient stays is an important element in the treatment of schizophrenia. There is a wide range of antipsychotic medications available ranging from conventional or typical first-generation antipsychotics, atypical second-generation antipsychotics, and conventional and atypical long-acting injectables (LAIs). What they all have in common is that the efficacy of the drugs is highly dependent on patient adherence. ${ }^{7}$ However, adherence levels are reported to be low among schizophrenia patients, ${ }^{8,9}$ and scientific evidence suggests a strong negative relationship between the level of adherence and the probability of hospitalization for patients in the United States ${ }^{10-17}$ and Europe; ${ }^{18,19}$ refer also, Higashi et al ${ }^{20}$ for a recent systematic review on this topic. They found lack of insight, medication beliefs, and substance abuse to be key drivers of nonadherence that in turn leads to a greater risk of relapse, hospitalization, and suicide.

We are not aware of any study that utilizes Japanese data to analyze the relationship between adherence and hospitalization. In our view, it is worth studying the
Correspondence: Jörg Mahlich Janssen Pharmaceutical KK 5-2, Nishi-kanda 3-chome Chiyoda-ku, Tokyo I0I-0065 Japan

Email jmahlich@its.jnj.com 
Japanese data because stigmatizing attitudes in response to mental disorders are reported to be more severe in Japan, ${ }^{21}$ which some authors attribute to the old Japanese character of the word schizophrenia which literally means "the disease of disorganized mind". ${ }^{22}$ In 2002, the Japanese name of schizophrenia was changed into "Togo Shitcho Sho" or "integration disorder" in an attempt to reduce discrimination and stigmatization. ${ }^{23}$ Stigmatization was such a major issue that only $7 \%$ of Japanese psychiatrists informed all their patients about the diagnosis of schizophrenia. Most of the time, the patients were kept in a state of uncertainty about their disease. ${ }^{24}$ Japanese were also found to be more reluctant to discuss mental disorders with others outside the family. ${ }^{25}$ Moreover, Japanese families are believed to think that a family member with schizophrenia should have care provided only by family members, which is argued to be deep-rooted in Confucian ideas. ${ }^{26,27}$ If this was true, we would expect only a weak relationship between poor adherence and hospitalization because the patient would be taken care of by the family when experiencing a mild relapse.

The aim of this study is to analyze the relationship between medication adherence and hospitalization in Japan using Japanese schizophrenia claims data. We address not only underadherence to medication but also the issue of overadherence that has recently been identified as a problem not only for schizophrenia ${ }^{28}$ but also for other indications. ${ }^{29}$ Within the framework of a multivariate regression analysis, we statistically assess factors that drive the rehospitalization of patients with schizophrenia within 6 months after a schizophrenia-related hospital discharge.

\section{Methods}

We analyzed a claims database provided by Japan Medical Data Center Co., Ltd. The Japan Medical Data Center Co., Ltd database is an employer-based database of health insurance claims with approximately 2.5 million beneficiaries. It covers 40 of approximately 1,500 Japanese health insurers and contains detailed electronic records of health insurance claim information on inpatient, outpatient, and prescription drug data at the individual member level over a specified period of time. The database contains data for 12,047 patients who have records for schizophrenia and antipsychotic agents (ATC code N05A) between January 1, 2009, and April 30, 2013 , in Japan. We restricted our analysis to patients between 18 years and 65 years of age who have a schizophrenia diagnosis (ICD-10 code "F20") and had a hospitalization discharge for schizophrenia within the research timeframe. This discharge hospitalization was labeled as their "index hospitalization". Patients must be prescribed an antipsychotic medicine (N05A) within a month following discharge. The index hospitalization was not counted as a hospitalization; instead, only hospitalizations that occurred after the index hospitalization were defined as an event in our multivariate regression analysis. Only hospital-stays of 7 days or longer were taken into consideration both for the index hospitalization and possible subsequent rehospitalizations because expert interviews indicated that hospital stays shorter than 7 days are probably due to incorrect coding and not schizophrenia related. Indeed, a recent investigation of more than 8,000 Japanese schizophrenia patients reported an average length of stay of 3,242 days. ${ }^{30}$

We identified 657 patients in our database who fulfilled our inclusion criteria. The main explanatory variable of interest is the adherence rate. We used the "Medication Possession Ratio" (MPR) that was calculated for antipsychotic agents. The MPR was calculated as the number of days' supply of medication divided by the number of days the patient was in the database from their index date (assuming patient should be on medication for the entire period). The average value of the 6-month interval following index hospitalization was used for the analysis. In case of an event (rehospitalization) during the 6-month interval, the average MPR value was taken for the time between index hospitalization and the event. Time within a nonpsychiatric hospitalization was included in this analysis as they should be receiving their psychiatric medications and the reason for hospitalization is not related to schizophrenia. We adjusted for the number of days of activity for LAIs such as Risperidone (Risperdal ${ }^{\circledR}$ Consta $^{\circledR}$ ) or Haloperidol Decanote. Risperdal ${ }^{\circledR}$ Consta $^{\circledR}$ for instance is a 14-day treatment; every dose was counted as 14 days' supply in the MPR calculation. Based on the calculated MPR value, we formed three groups: MPR $<0.8$ (poor adherence), $0.8 \leq \mathrm{MPR} \leq 1.1$ (good adherence), and MPR $>1.1$ (overadherence). This classification is in line with Valenstein et al. ${ }^{14}$ It should be noted that this adherence measure is based on the number of collected prescriptions. It does not necessarily mean that the received medication was also taken.

We included the following control variables in the model:

\section{Age}

If the proposition is true that family members in Japan are substantially involved in providing care, we might observe a positive age effect. While parents are probably able to look after their children with schizophrenia up to a certain age, 
older patients might find it more difficult to receive family support as a substitute for hospitalization.

\section{Sex}

Some authors suggest that men suffer more negative symptoms and more severe course of illness than women, which would suggest a higher hospitalization probability of men. ${ }^{31-33}$

\section{Insurance type}

Most claims data analyses include the insurance type as an explanatory variable; for instance, refer Suh et al for a Korean study. ${ }^{34}$ In our case, insurance type is either an individual membership or being insured as a family member. For the insurance type "individual member", our employer-based database is biased in that it does not cover unemployed persons. The employment rate of Japanese patients with schizophrenia is less than $30 \%,{ }^{2}$ and patients suffering from a severe form of schizophrenia are probably underrepresented in the database. Note that there is a $100 \%$ employment ratio of individual members in our database. On the other hand, there is no such employment bias for family members. Hence, we expect family members to be more often hospitalized than individual members, because family membership is not linked to employment status.

\section{Comorbidities}

People with schizophrenia have a wide range of multiplecomorbid physical health problems including alcohol abuse compared with people without schizophrenia. ${ }^{35,36}$ We expect people with comorbidities to be rehospitalized more often.

\section{Length of index hospitalization}

The length of the index hospitalization captures the disease severity and we also expect a positive impact of this variable.

For the statistical analysis, we employed a multivariate Cox proportional hazard model. ${ }^{37}$ For the coefficients, a significance level of $10 \%$ was chosen, which is a common threshold within the framework of real-world data analysis. $^{38}$

\section{Results and discussion}

Table 1 provides an overview of the sample population. It can be seen that only a small fraction of $25.9 \%$ can be classified as adherent (MPR between 0.8 and 1.1). Surprisingly, the majority $(51 \%)$ of the patients belong to the overadherence group where the number of prescriptions would cover more than $110 \%$ of the required time. Only $26 \%$ of the patients are in the good-adherence group.

The regression results of the Cox model are displayed in Table 2. According to these results, family member type, presence of a bipolar and anxiety disorder, and both poor adherence and overadherence are associated with a higher risk of rehospitalization. The hazard ratios are 4.7 for the poor-adherence group and 2.0 for the overadherence group. The whole model was statistically significant yielding a Likelihood $P$-value of 0.0013 .

The results suggest that the medication adherence of schizophrenia patients as measured by the MPR is significantly related to the likelihood of rehospitalization. Both the poor-adherence group as well as the overadherence group face a higher chance of rehospitalization compared to the good-adherence group. The effect is most pronounced in the

Table I Description of the sample $(n=657)$

\begin{tabular}{lll}
\hline Variables & & \\
\hline Adherence (MPR) & $<0.8, \mathrm{~N}(\%)$ & $15 \mathrm{I}(22.98)$ \\
& $0.8 \leq \mathrm{MPR} \leq \mathrm{I} . \mathrm{I}, \mathrm{N}(\%)$ & $170(25.88)$ \\
& $>\mathrm{I} . \mathrm{I}, \mathrm{N}(\%)$ & $336(5 \mathrm{I} .14)$ \\
Age & Mean \pm SD & $38.28 \pm \mathrm{I} 2.38$ \\
Alcohol abusers & $\mathrm{N}(\%)$ & $23(3.50)$ \\
Length of index hospitalization & Mean \pm SD & $84.33 \pm 149.42$ \\
Sex & Male, N (\%) & $222(33.79)$ \\
& Female, N (\%) & $435(66.21)$ \\
Insurance type & Individual, N (\%) & $189(28.77)$ \\
Comorbidities & Family, N (\%) & $468(71.23)$ \\
& Anxiety disorder, N (\%) & $105(15.98)$ \\
Patients with rehospitalization & Bipolar disorder, N (\%) & $197(29.98)$ \\
\hline
\end{tabular}

Abbreviations: MPR, medication possession ratio; SD, standard deviation. 
Table 2 Regression results

\begin{tabular}{|c|c|c|}
\hline Variables & Hazard ratio & $P$-value \\
\hline Age, years & 1.017 & 0.1777 \\
\hline Sex: female & 0.698 & 0.3154 \\
\hline \multicolumn{3}{|l|}{ Reference group: male } \\
\hline Member type: family & $2.84 I$ & 0.0234 \\
\hline \multicolumn{3}{|l|}{ Reference group: individual member } \\
\hline Length of index hospitalization, days & 0.999 & 0.4662 \\
\hline Bipolar disorder & 1.641 & 0.0798 \\
\hline \multicolumn{3}{|l|}{ Reference group: no bipolar disorder } \\
\hline Major depression & 1.039 & 0.8869 \\
\hline \multicolumn{3}{|l|}{ Reference group: no major depression } \\
\hline Anxiety disorder & 2.028 & 0.0161 \\
\hline \multicolumn{3}{|l|}{ Reference group: no anxiety disorder } \\
\hline Alcohol abuse & 0.708 & 0.7373 \\
\hline \multicolumn{3}{|l|}{ Reference group: no alcohol abuse } \\
\hline MPR (0-6 months): MPR $<0.8$ & 4.719 & 0.0004 \\
\hline \multicolumn{3}{|l|}{ Reference group: $0.80 \leq \mathrm{MPR} \leq \mathrm{I} . \mathrm{I}$} \\
\hline MPR (0-6 months): MPR >I.I & 2.007 & 0.0858 \\
\hline Reference group: $0.8 \leq \mathrm{MPR} \leq \mathrm{I} . \mathrm{I}$ & & \\
\hline
\end{tabular}

Notes: Likelihood ratio test: $P=0.0013$. Bold values represent significance at the $10 \%$ level or better.

Abbreviation: MPR, medication possession ratio.

poor-adherence group. This result is in line with international studies that were undertaken in other cultural environments. Valenstein et a ${ }^{14}$ who used the same definition of adherence found that patients with both poor adherence and excess medication fills had higher psychiatric admission rates than patients with good adherence in the United States. We therefore do not observe a specific "Japan effect" as hypothesized in the introduction. Nevertheless, this study contributes to the existing evidence in emphasizing the importance of medication adherence in the treatment of schizophrenia patients. There are several ways to improve patient's adherence. One possible option from a clinical point of view is treatment with LAIs because evidence suggests that LAIs improve patient's adherence and eventually reduce hospital stays. ${ }^{39-43}$ Accordingly, several cost-effectiveness studies demonstrated economic superiority of LAIs over oral antipsychotics. ${ }^{44} 48$ Spill et al for instance observed patients who switched from an oral treatment to risperidone LAI in the framework of a mirror image design study. They report overall savings in drug and institutional-care costs of $21.1 \%$ after 1 year. ${ }^{49}$

On the other hand, Waddell and Tylor found that LAIs continue to have an image problem among patients and mental health staff and are primarily used as a "last resort" for the most stigmatized individuals. ${ }^{50}$ For this reason, the utilization of LAIs is still low despite their clinical and economic benefits.

The high percentage of patients who are overadherent (51\%) is also worth noting. A US claims data analysis found only $7.6 \%$ of patients with medication oversupply. ${ }^{26}$ As we only included patients who have been hospitalized, this gap might be due to differences in the respective patient populations. However, this seems to be only part of the story as a US observational study of patients who are discharged with schizophrenia found only $21 \%$ of patients received doses in excess of recommended levels. ${ }^{51}$ Institutional factors of the Japanese prescription drug market might serve as an alternative explanation. ${ }^{52}$ As we only observe the number of prescriptions and not the intake of the medication, the issue of overadherence should be studied in more detail in future research. Although our results suggest a correlation between overadherence and hospitalization, we do know little about potential causal relationships. One possible explanation is we could not adequately control for disease severity. If illness severity and oversupply of medication are correlated, the observed increased hospitalization rates would be a consequence of the disease severity and not necessarily of overmedication itself.

When it comes to our control variables, we observe that family members are more likely to be rehospitalized than individual members, which can be attributed to the employment bias of the databank we used. Psychiatric comorbidities such as anxiety disorder also contribute to the risk of rehospitalization. Patients with comorbidities are more difficult to treat in an outpatient setting or within the family. Although the variables age and sex are not significant drivers of rehospitalization, the hazard ratios have the expected values of greater than 1 and less than 1, respectively. Both male sex and age are associated with a higher risk. With regard to sex, it is well described in the literature that women with schizophrenia score better both in social ${ }^{53,54}$ and cognitive functioning, ${ }^{55,56}$ which probably influences the need for inpatient treatment.

\section{Conclusion}

The results of this study confirm the notion that good adherence with antipsychotic medication reduces the risk of rehospitalization of schizophrenia patients. Relevant stakeholders should collaboratively aim at improving patient adherence to prevent unnecessary hospital stays. Overadherence seems to be another issue that needs further attention. As health insurers are able to identify poorly adherent insured patients in their data, a timely intervention in collaboration with medical care providers would be desirable.

\section{Disclosure}

HK, YS, and JM are employees of Janssen that sells and markets drugs for the treatment of schizophrenia. 


\section{References}

1. Rössler W, Salize HJ, van Os J, Riecher-Rössler A. Size of burden of schizophrenia and psychotic disorders. Eur Neuropsychopharmacol. 2005;15(4):399-409.

2. Sado M, Inagaki A, Koreki A, et al. The cost of schizophrenia in Japan. Neuropsychiatr Dis Treat. 2013;9:787-798.

3. Lin I, Muser E, Munsell M, Benson C, Menzin J. Economic impact of psychiatric relapse and recidivism among adults with schizophrenia recently released from incarceration: a Markov model analysis. $J \mathrm{Med}$ Econ. 2014;26:1-11.

4. Fitch K, Iwasaki K, Villa K. Resource utilization and cost in a commercially insured population with schizophrenia. Am Health Drug Benefits. 2014;7(1):18-26.

5. Willis M, Svensson M, Löthgren M, Eriksson B, Berntsson A, Persson U. The impact of schizophrenia-related hospital utilization and cost of switching to long-acting risperidone injections in Sweden. Eur J Health Econ. 2010;11(6):585-594.

6. Frey S. The economic burden of schizophrenia in Germany: a population-based retrospective cohort study using genetic matching. Eur Psychiatry. 2014;29(8):479-489.

7. Menzin J, Boulanger L, Friedman M, Mackell J, Lloyd JR. Treatment adherence associated with conventional and atypical antipsychotics in a large state Medicaid program. Psychiatr Serv. 2003;54(5):719-723.

8. Rummel-Kluge C, Schuster T, Peters S, Kissling W. Partial compliance with antipsychotic medication is common in patients with schizophrenia. Aust N Z J Psychiatry. 2008;42(5):382-388.

9. Marder SR. Overview of partial compliance. J Clin Psychiatry. 2003;64(suppl 16):3-9.

10. Lang K, Meyers JL, Korn JR, et al. Medication adherence and hospitalization among patients with schizophrenia treated with antipsychotics. Psychiatr Serv. 2010;61(12):1239-1247.

11. Tafesse E, Hines PL, Carson W. Atypical antipsychotic adherence and hospitalization in patients with schizophrenia. Schizophr Res. 2003;60:346

12. Ascher-Svanum H, Zhu B, Faries D, Lacro JP, Dolder CR. A prospective study of risk factors for nonadherence with antipsychotic medication in the treatment of schizophrenia. J Clin Psychiatry. 2006;67: 1114-1123.

13. Eaddy M, Grogg A, Locklear J. Assessment of compliance with antipsychotic treatment and resource utilization in a Medicaid population. Clin Ther. 2005;27:263-272.

14. Valenstein M, Copeland L, Blow F, et al. Pharmacy data identify poorly adherent patients with schizophrenia at increased risk for admission. Med Care. 2002;40:630-639.

15. Ahn J, McCombs J, Jung C, et al. Classifying patients by antipsychotic adherence patterns using latent class analysis: characteristics of nonadherent groups in the California Medicaid (Medi-Cal) program. Value Health. 2008;11:48-56.

16. Kozma C, Weiden P. Partial compliance with antipsychotics increases mental health hospitalizations in schizophrenic patients: analysis of a national managed care database. Am Health Drug Benefits. 2009;2:31-38.

17. Gilmer T, Dolder C, Lacro J, et al. Adherence to treatment with antipsychotic medication and health care costs among Medicaid beneficiaries with schizophrenia. Am J Psychiatry. 2004;161:692-699.

18. Morken G, Widen J, Grawe R. Nonadherence to antipsychotic medication, relapse and rehospitalisation in recent-onset schizophrenia. $B M C$ Psychiatry. 2008;8:32.

19. Knapp M, King D, Pugner K, Lapuerta P. Non-adherence to antipsychotic medication regimens: associations with resource use and costs. Br J Psychiatry. 2004;184:509-516.

20. Higashi K, Medic G, Littlewood KJ, Diez T, Granström O, De Hert M. Medication adherence in schizophrenia: factors influencing adherence and consequences of nonadherence, a systematic literature review. Ther Adv Psychopharmacol. 2013;3(4):200-218.

21. Griffiths KM, Nakane Y, Christensen H, Yoshioka K, Jorm AF, Nakane H. Stigma in response to mental disorders: a comparison of Australia and Japan. BMC Psychiatry. 2006;6:21.
22. Kim Y, Berrios GE. Impact of the term schizophrenia on the culture of ideograph: the Japanese experience. Schizophr Bull. 2001;27(2): 181-185.

23. Sato M. Renaming schizophrenia: a Japanese perspective. World Psychiatry. 2006;5(1):53-55.

24. Ono Y, Satsumi Y, Kim Y, et al. Schizophrenia: is it time to replace the term? Psychiatry Clin Neurosci. 1999;53:335-341.

25. Jorm AF, Nakane Y, Christensen H, Yoshioka K, Griffiths KM, Wata Y. Public beliefs about treatment and outcome of mental disorders: a comparison of Australia and Japan. BMC Med. 2005;3:12.

26. Hanzawa S, Nosaki A, Yatabe K, et al. Study of understanding the internalized stigma of schizophrenia in psychiatric nurses in Japan. Psychiatry Clin Neurosci. 2012;66:113-120.

27. Hanzawa S, Bae JK, Tanaka H, et al. Family stigma and care burden of schizophrenia patients: comparison between Japan and Korea. AsiaPacific Psychiatry. 2009;1:120-129.

28. Yang M, Barner J, Worchel J. Factors related to antipsychotic oversupply among central Texas veterans. Clin Ther. 2007;29(6): 1214-1225.

29. Gray SL, Mahoney JE, Blough DK. Medication adherence in elderly patients receiving home health services following hospital discharge. Ann Pharmacother. 2001;35(5):539-545.

30. Sugibayashi Y, Yoshimura K, Yamauchi K, Inagaki A, Ikegami N. Influence of patient characteristics on care time in patients hospitalized with schizophrenia. Neuropsychiatr Dis Treat. 2014;10: 1577-1584.

31. Ochoa S, Usall J, Cobo J, Labad X, Kulkarni J. Gender differences in schizophrenia and first-episode psychosis: a comprehensive literature review. Schizophr Res Treatment. 2012;2012:916198.

32. Shtasel D, Gur R, Gallacher F, Heimberg C, Gur R. Gender differences in the clinical expression of schizophrenia. Schizophr Res. 1992;7(3):225-231.

33. Bergen SE, O'Dushlaine CT, Lee PH, et al. Genetic modifiers and subtypes in schizophrenia: investigations of age at onset, severity, sex and family history. Schizophr Res. 2014;154(1-3):48-53.

34. Suh HS, Kang HY, Kim J, Shin E. Effect of health insurance type on health care utilization in patients with hypertension: a national health insurance database study in Korea. BMC Health Serv Res. 2014;14:570.

35. Smith DJ, Langan J, McLean G, Guthrie B, Mercer SW. Schizophrenia is associated with excess multiple physical-health comorbidities but low levels of recorded cardiovascular disease in primary care: crosssectional study. BMJ Open. 2013;3:e02808.

36. Buckley PF, Miller BJ, Lehrer DS, Castle DJ. Psychiatric comorbidities and schizophrenia. Schizophr Bull. 2009;35(2):383-402.

37. Cox DR. Regression models and life tables (with discussion). J R Stat Soc B. 1972;34:187-220.

38. Maddala GS. Introduction to Econometrics. 3rd ed. New York: John Wiley and Sons; 2001.

39. Acosta FJ, Bosch E, Sarmiento G, Juanes N, Caballero-Hidalgo A, Mayans T. Evaluation of noncompliance in schizophrenia patients using electronic monitoring (MEMS) and its relationship to sociodemographic, clinical and psychopathological variables. Schizophr Res. 2009;107(2):213-217.

40. Tiihonen J, Haukka J, Taylor M, Haddad PM, Patel MX, Korhonen P. A nationwide cohort study of oral and depot antipsychotics after first hospitalization for schizophrenia. Am J Psychiatry. 2011;168(6):603-609.

41. Grimaldi-Bensouda L, Rouillon F, Astruc B, et al; CGS Study Group. Does long-acting injectable risperidone make a difference to the real-life treatment of schizophrenia? Results of the Cohort for the General study of Schizophrenia (CGS). Schizophr Res. 2012;134(2-3):187-194.

42. Leucht C, Heres S, Kane JM, Kissling W, Davis JM, Leucht S. Oral versus depot antipsychotic drugs for schizophrenia - a critical systematic review and meta-analysis of randomised long-term trials. Schizophr Res. 2011;127(1-3):83-92.

43. Rossi G, Frediani S, Rossi R, Rossi A. Long-acting antipsychotic drugs for the treatment of schizophrenia: use in daily practice from naturalistic observations. BMC Psychiatry. 2012;12:122. 
44. Olivares JM, Rodriguez-Morales A, Diels J, et al; e-STAR Spanish Study Group. Long-term outcomes in patients with schizophrenia treated with risperidone long-acting injection or oral antipsychotics in Spain: results from the electronic Schizophrenia Treatment Adherence Registry (e-STAR). Eur Psychiatry. 2009;24(5):287-296.

45. Olivares JM, Rodriguez-Martinez A, Burón JA, Alonso-Escolano D, Rodriguez-Morales A; e-STAR Study Group. Cost-effectiveness analysis of switching antipsychotic medication to long-acting injectable risperidone in patients with schizophrenia: a 12- and 24-month follow-up from the e-STAR database in Spain. Appl Health Econ Health Policy. 2008;6(1):41-53.

46. Gaebel W, Schreiner A, Bergmans P, et al. Relapse prevention in schizophrenia and schizoaffective disorder with risperidone long-acting injectable vs quetiapine: results of a long-term, open-label. Randomized clinical trial. Neuropsychopharmacology. 2010;35(12):2367-2377.

47. Zeidler J, Mahlich J, Greiner W, Heres S. Cost-effectiveness of paliperidone palmitate for the treatment of schizophrenia in Germany. Appl Health Econ Health Policy. 2013;11(5):509-521.

48. Ransmayr S, Mehnert A, Mahlich J. Budget impact analyse von Paliperidon Palmitat im österreichischen Versorgungskontext. [Budget impact analysis of paliperdidone palmitate in the Austrian health care system]. Pharmacoecon Ger Res Artic. 2013;11:25-32. German.

49. Spill B, Konoppa S, Kissling W, Maino K, Messer T, Heres S. Longterm observation of patients successfully switched to risperidone longacting injectable: a retrospective, naturalistic 18-month mirror-image study of hospitalization rates and therapy costs. Int J Psychiatry Clin Pract. 2010;14:53-62.
50. Waddell L, Taylor M. Attitudes of patients and mental health staff to antipsychotic long-acting injections: systematic review. Br JPsychiatry. 2009; 195:s43-s50.

51. Walkup JT, McAlpine DD, Olfson M, Labay LE, Boyer C, Hansell S. Patients with schizophrenia at risk for excessive antipsychotic dosing. J Clin Psychiatry. 2000;61(5):344-348.

52. Iizuka T. Experts' agency problems: evidence from the prescription drug market in Japan. Rand J Econ. 2007;38(3):844-862.

53. Vila-Rodriguez F, Ochoa S, Autonell J, Usall J, Haro JM. Complex interaction between symptoms, social factors, and gender in social functioning in a community-dwelling sample of schizophrenia. Psychiatric Q. 2011;82(4):261-274.

54. Grossman LS, Harrow M, Rosen C, Faull R, Strauss GP. Sex differences in schizophrenia and other psychotic disorders: a 20-year longitudinal study of psychosis and recovery. Compr Psychiatry. 2008;49(6):523-529.

55. Vaskinn A, Sundet K, Simonsen C, Hellvin T, Melle I, Andreassen OA. Sex differences in neuropsychological performance and social functioning in schizophrenia and bipolar disorder. Neuropsychology. 2011;25(4):499-510.

56. Bozikas VP, Kosmidis MH, Peltekis A, et al. Sex differences in neuropsychological functioning among schizophrenia patients. Aust NZJ Psychiatry. 2010;44(4):333-341.
Neuropsychiatric Disease and Treatment

\section{Publish your work in this journal}

Neuropsychiatric Disease and Treatment is an international, peerreviewed journal of clinical therapeutics and pharmacology focusing on concise rapid reporting of clinical or pre-clinical studies on a range of neuropsychiatric and neurological disorders. This journal is indexed on PubMed Central, the 'PsycINFO' database and CAS,

\section{Dovepress}

and is the official journal of The International Neuropsychiatric Association (INA). The manuscript management system is completely online and includes a very quick and fair peer-review system, which is all easy to use. Visit http://www.dovepress.com/testimonials.php to read real quotes from published authors. 